\title{
Narrativas e memória sobre a revista Intervalo: metodologia de História Oral a serviço da pesquisa sobre a história da imprensa
}

\author{
Talita Souza Magnolo* \\ ORCID iD 0000-0002-6240-388X \\ Universidade Federal de Juiz de Fora, Minas Gerais, Brasil \\ Rosali Maria Nunes Henriques* \\ ORCID iD 0000-0003-1688-04474 \\ Universidade Nova de Lisboa, Portugal
}

Resumo: Este artigo tem como objetivo discutir alguns conceitos, aspectos e diferentes percepçóes com relação à importância da preservaçáo da memória. Parte-se do pressuposto que a memória recente não é reconstituída somente pela metodologia da História Oral, mas também através de documentos, arquivos, fotos, entre outras fontes que são capazes de guardar resíduos e rastros do passado. Nosso objeto de pesquisa será a revista Intervalo (1963-1972), da Editora Abril. A experiência com a realização de entrevistas com ex-funcionários da Intervalo permitiu que a história da revista fosse registrada e que houvesse um melhor entendimento do contexto histórico do período. Analisaremos, através de trechos dos depoimentos colhidos, alguns aspectos e estratégias de comunicação por parte da revista, que foi reforçada pela criação e disseminação de programas televisivos - programas musicais, quiz shows, entrevistas, programas humorísticos, competiçóes musicais, entre outros - como grande estratégia de marketing por parte das emissoras de TV.

Palavras-chave: História Oral. Revista Intervalo. Entrevistas. Televisão. Memória.

Mestre e doutoranda em Comunicação pelo Programa de Pós-Graduação em Comunicação da Universidade Federal de Juiz de Fora (UFJF), Minas Gerais, Brasil. E-mail: talita.magnolo@yahoo. com.br.

* Doutora em Memória Social pela Universidade Federal do Estado do Rio de Janeiro (Unirio), com orientação da Profa. Dra. Vera Dodebei. E-mail: rosalih@gmail.com. 


\title{
Narratives and memory about the Intervalo magazine: \\ Oral History methodology at the service of research on the history of the press
}

\begin{abstract}
This article aims to discuss some concepts, aspects and different perceptions regarding the importance of memory preservation. It is based on the assumption that recent memory is not only reconstructed by the Oral History methodology, but also through documents, files, photos, among other sources that are capable of storing residues and traces of the past. Our research object will be Editora Abril's magazine Intervalo (1963-1972). The experience of conducting interviews with former Intervalo employees allowed the magazine's history to be recorded and a better understanding of the historical context of the period. We will analyze, through excerpts from the testimonies collected, some aspects and communication strategies by the magazine, which was reinforced by the creation and dissemination of television programs - musical programs, quiz shows, interviews, humorous programs, musical competitions, among others - as a major marketing strategy by TV stations.
\end{abstract}

Keywords: Oral History. Intervalo magazine. Interviews. TV. Memory.

\section{Introdução}

A revista Intervalo é uma das mais conhecidas publicaçóes brasileiras sobre televisão das décadas de 1960 e 1970 . Ao questionar as pessoas que viveram nesse período, muitas se lembraram, quase sempre de forma vaga, desse semanário da Editora Abril. Para quem náo viveu nesse período, pode parecer o contrário, mas as revistas que existiram nessa época fizeram história, algumas por serem mais modernas e ousadas, como foi o caso da revista Realidade, também da Editora Abril, outras por representarem o conservadorismo e a tradição, como aconteceu com O Cruzeiro, dos Diários Associados de Assis Chateaubriand, e a Intervalo, por exemplo, que foi a primeira revista a tratar exclusivamente sobre assuntos relacionados à televisáo. A história se perde quando seus acontecimentos e personagens do passado não são repassados adiante, seja pela oralidade ou pela escrita. Isso aconteceu com o semanário da Editora Abril que existiu entre 1963 e 1972. Sua trajetória e memória se perderam no tempo. Atualmente, não é tăo fácil localizar informaçôes sobre as suas principais características e singularidades. Não havendo informaçóes através de fontes mais tradicionais - livros, mídia, internet, artigos, dissertaçóes ou teses - precisou-se pensar além e tentar, através da metodologia da História Oral, localizar possíveis fontes que pudessem compartilhar suas experiências e vivências na revista. Para isso, realizamos entrevistas com os ex-funcionários da revista Intervalo e da Editora Abril com o intuito de entender a sua trajetória. As entrevistas foram temáticas, tendo como foco a história e principais características da revista, mas também buscando captar a efervescência cultural, musical e midiática dos anos 1960.

Os astros e celebridades, portanto, ocuparam cada vez com mais frequência as páginas da revista, que se comportou como uma porta-voz da televisáo e fez sua fama em cima dos mais variados assuntos de TV e pela disseminação - de forma inovadora 
no Brasil - da programação televisiva brasileira.
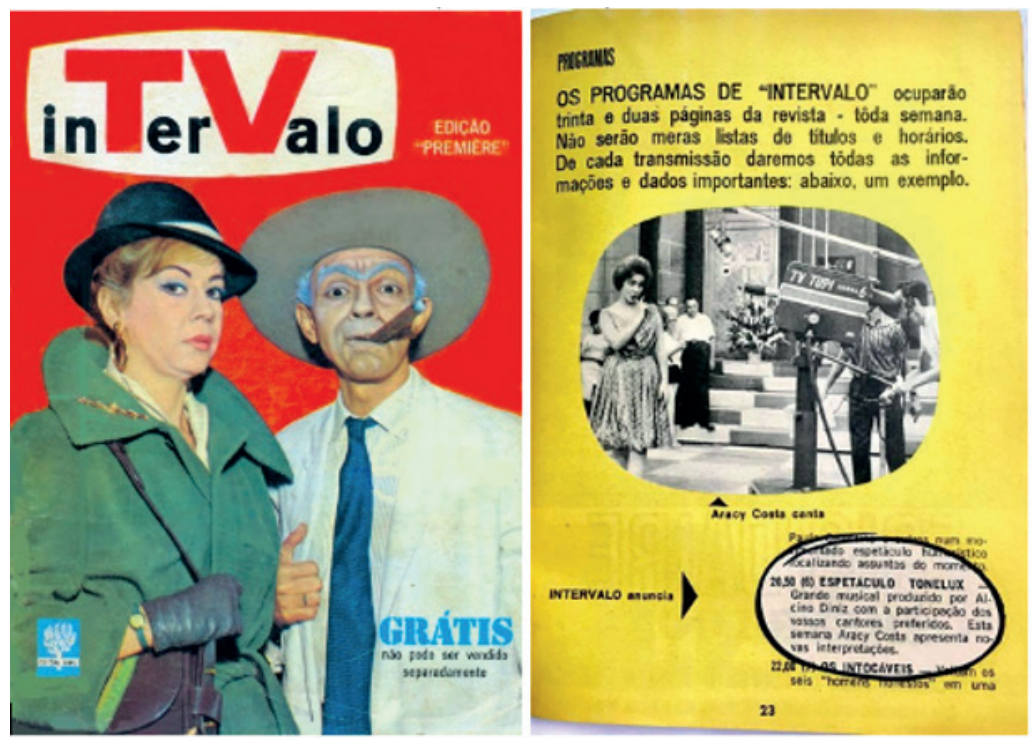

Imagem 1- Revista Intervalon. 0: capa e página 23 (06/01/1962).

Fonte: acervo pessoal de Talita Souza Magnolo. ${ }^{1}$

Para este trabalho, buscamos observar as narrativas orais como fontes que permitiráo o conhecimento aprofundado de episódios históricos, grupos sociais e história individual de cada depoente e seu sentimento com relação a um determinado contexto do período analisado. As lembranças são a melhor forma de recuperação da consciência dos acontecimentos passados e a memória por si só é rica em manifestaçóes, desde o próprio ato de lembrar até a reconstituição de algum ambiente, espaço, hábitos, práticas, comportamentos, valores e crenças. Através da entrevista buscamos despertar nos entrevistados as emoçóes individuais ou coletivas por meio de algum gatilho emocional - no nosso caso, isso foi feito com a apresentaçáo de fotos ou exemplares da revista - sempre lembrando que os depoimentos possuem uma construçáo subjetiva, como anunciado por David (2013, p. 159): "No campo da memória, o indivíduo relembra seu passado seguindo a perspectiva colocada em pauta pelo pesquisador".

Pesquisar sobre a revista Intervalo é contribuir para esse processo de rememoração produtiva, especialmente com a reconstituição da história da revista junto aos jornalistas

A maioria das imagens utilizadas neste artigo são fotografias feitas de edições originais da revista Intervalo que compõem acervo pessoal de Talita Souza Magnolo. O exemplares foram doações dos entrevistados ou adquiridas em sebos. É importante ressaltar que o site da Hemeroteca Digital da Biblioteca Nacional possui, atualmente, um grande acervo das revistas digitalizadas. Entretanto, as imagens estão em preto e branco e em qualidade inferior às fotografias por nós utilizadas. 
e diretores que trabalhavam na Editora Abril durante os anos 1960. Buscamos desvendar os contextos político, social e cultural de um período que já tem muito a nos contar, porém, acreditamos que os depoimentos tornaram possível resgatar e descobrir novas histórias e memórias que ainda não foram compartilhadas.

A História Oral é a metodologia de pesquisa que utilizamos para registrar as memórias dos ex-funcionários da revista Intervalo. Ela consiste em realizar entrevistas gravadas com pessoas que podem testemunhar sobre acontecimentos, conjunturas, instituiçóes, modos de vida ou outros aspectos da história contemporânea. Tomamos as entrevistas como fontes para a compreensão do passado, ao lado de documentos escritos, imagens e outros tipos de registro. A oralidade na visão de Benjamin (2012) é refletida pelo o que autor chamou de "narrador clássico", aquele que recorre à experiência que passa de boca em boca. ${ }^{2} \mathrm{O}$ narrador original é aquele que sabe dar conselhos, possui em si o acervo de toda uma vida e de experiências alheias. Ele produz, cria e ressignifica.

Ela [a verdadeira narrativa] traz sempre consigo, de forma aberta ou latente, uma utilidade. Essa utilidade pode consistir por vezes num ensinamento moral, ou numa sugestão prática, ou também num provérbio ou norma de vida - de qualquer maneira, o narrador é um homem que sabe dar conselhos ao ouvinte. Mas, se 'dar conselhos' soa hoje como algo antiquado, isto se deve ao fato de as experiências estarem perdendo a sua comunicabilidade. (Benjamin, 2012, p. 216).

A metodologia de História Oral grava as histórias de vida das pessoas - contadas por elas mesmas - e representa uma forma de entender o que é, como se faz e para que serve os registros históricos. Para a nossa pesquisa, será importante considerarmos que toda história é uma narrativa, ou seja, ela nunca está pronta e será sempre narrada por alguém através de um processo vivo, permanente e subjetivo. Por mais que os depoimentos falem do passado, a memória é registrada e contada no presente e, de acordo com a percepçáo de cada uma, ela pode mudar. Outro aspecto que também será levado em consideração é que esse processo é feito pelos indivíduos, isto é, todo entrevistado é personagem ou autor da história - de um lado, ele faz parte e se relaciona com os acontecimentos e de outro, participa da autoria desse registro (Portelli, 2016).

\section{A construção das narrativas e a memória}

O intenso fluxo de informações que está inundando o mundo globalizado, por

2 Deve-se ressaltar o contexto e período em que Benjamin levanta essas questões: o texto "O Narrador" é originalmente de 1936, um período entre guerras - a Primeira e a Segunda Guerra Mundial - em que os soldados voltavam dos campos de batalha pobres em experiências comunicáveis e a história oral dá lugar a romances mais realistas com uma tendência à vanguarda experimental 
vezes, dá a falsa sensação de que conhecemos a riqueza da sociedade. Andreas Huyssen (2014) afirma que o crescimento da cultura da memória ganhou força a partir dos anos 1970 e 1980, e atingiu proporçóes inimagináveis na década de 1990, fazendo com que o comportamento humano valorizasse o passado em detrimento à excessiva importância que se dava ao futuro, como aconteceu no início do século XX. Huyssen (2014) assinala que a cultura modernista que se fundamentava no ideal de "futuros presentes" começou a se sobrepor ao futurismo, desde a década de 1980, fazendo com que a cultura geral se voltasse para os acontecimentos passados. Para ele, nossa relação com o passado se faz presente desde registros mais simplórios à criaçáo de monumentos, museus e bibliotecas - para documentar e registrar as mudanças socioeconômicas, ambientais e culturais de sociedades, pessoas, acontecimentos - e projetos que valorizam depoimentos orais e as histórias de vida.

Segundo Huyssen (2000), o excesso de informação produzida pela sociedade na atualidade e os mais variados estudos sobre a memória trazem sua supervalorizaçáo enquanto um possível campo de estudo, sendo assim, esses vastos estudos e pesquisas trazem elementos específicos e únicos para a discussão sobre qualquer tema da atualidade - principalmente por ser interdisciplinar -, abrangendo discussóes que vão desde a preservação física, até discussóes técnicas sobre os procedimentos de coleta e de gravação dos depoimentos orais, trazendo elementos ricos para a análise de processos históricos e culturais de determinado grupo social em determinado período.

Ao mesmo tempo, a sociedade contemporânea é vista por Nora (1993) como uma sociedade sem memória, de memória "curta", e esse motivo leva a uma necessidade cada vez maior de se criarem dispositivos de armazenamento da memória. Esse movimento de retorno à memória fez com que historiadores e pesquisadores buscassem por arquivos que a conservassem. É fato que a escrita foi uma das primeiras formas responsáveis por esse tipo de preservação, mas, com o advento das novas tecnologias principalmente a partir do século XX - a perspectiva de suportes inéditos se ampliou exponencialmente. Para o autor, a necessidade que a sociedade tem da memória é, na verdade, uma necessidade da história. A busca pela memória, portanto, vai mudar a relaçáo que as pessoas têm com o passado e a história, por conta da rapidez e da correria do cotidiano e do desenvolvimento da tecnologia de informação.

Pollak (1992) argumenta que a memória pode ser formada por três elementos constitutivos: acontecimentos, personagens e lugares. O sociólogo e o historiador trabalham com esses elementos de forma individual e coletiva, já que o raciocínio perpassa pelas experiências vividas pela própria pessoa ou pelo contexto em que ela está inserida, ainda que seu envolvimento náo seja de maneira direta. Dessa forma, quando usamos a metodologia de História Oral, devemos considerar que os acontecimentos vividos pelo entrevistado estão em primeiro lugar, em segundo lugar os acontecimentos vivenciados pelo grupo ou pela coletividade a qual a pessoa pertence e em terceiro lugar, os acontecimentos fora do espaço-tempo, ou seja, por meio de uma socialização 
política ou histórica, um fenômeno de projeção ou de identificação com determinado passado que o autor chama de memória herdada.

As personagens também são entendidas dessa forma, existindo aquelas que foram encontradas pessoalmente, as que foram conhecidas de maneira indireta e aquelas que não pertenceram ao espaço-tempo da pessoa. Por último, Pollak (1992) analisa em seus trabalhos os lugares da memória ligados a uma lembrança, que pode ser pessoal, mas pode não ter relaçáo com o tempo cronológico - podendo ser um espaço ou uma revista onde trabalhou que tenha ficado marcado em sua na memória, independente da data real. O que vai definir a importância do momento são as vivências e experiências das pessoas do próprio grupo em relação ao objeto. Pode-se afirmar que a memória de um grupo está intimamente ligada as suas experiências e julgamentos internos, ou seja, ela é ao mesmo tempo seletiva e um fenômeno construído, pois para Pollak (1992, p. 203-204), "A memória é seletiva. Nem tudo fica gravado. Nem tudo fica registrado. A memória é, em parte, herdada, não se refere apenas à vida física da pessoa [...]. A memória é um fenômeno construído".

A partir desse aspecto, Halbwachs (1990) afirma que a linguagem é um dos elementos essenciais no processo de lembrança e esquecimento, pois ajuda a construir o caráter social da memória, visto que é através dela que acontecem as trocas dentro de um mesmo grupo. A linguagem, portanto, é um "instrumento socializador da memória" - unificando e aproximando em um mesmo espaço cultural e histórico diferentes vivências e experiências. Halbwachs (1990) aponta que as memórias alheias podem penetrar o inconsciente do sujeito através do próprio convívio, mas também pela cultura - através de livros, músicas, pinturas e outras formas de arte. Sendo assim, pode-se concluir que a memória coletiva é uma construção social, considerando que o homem é um ser social e está em constante evolução. O que permanece na memória do indivíduo - e é por ele exteriorizado conscientemente - se relaciona com o seu lugar no mundo, ou seja, depende de sua posição no tempo e no espaço.

A memória é seletiva, não guardamos tudo, mas apenas uma parcela do que nos aconteceu durante a vida, ou é assim que lembramos. E nem sempre o que guardamos é aquilo que queremos e nem o que selecionamos propositalmente, mas o que restou em nossa memória, pois, como afirma Le Goff (2003, p. 25): “O passado é uma construção e uma reinterpretação constante e tem um futuro que é parte integrante e significativa da história"

Ao discutirmos os conceitos de memória e de narrativa é preciso deixar claro de que memória estamos falando. A memória enquanto processo de lembrança e esquecimento ou os processos de rememoraçáo? Segundo Pomian (2000, p. 507), quando falamos em memória estamos falando em vestígios; e os vestígios são representaçôes da realidade, pois "toda memória é em primeiro lugar uma faculdade de conservar os vestígios do que pertence já em si a uma época passada". No entanto, toda reconstrução do passado é sempre imperfeita porque é marcada pela dúvida. E a arte da memória, na visão de Pomian, é a arte da linguagem, pois é a partir das narrativas orais ou escritas 
que um indivíduo se torna depositário da memória de seu grupo. É o que podemos chamar de memória coletiva. Mas, podemos afirmar que a memória possui um caráter virtual ou é apenas uma reprodução do físico, pois, segundo Bergson (2010, p. 158), "Essencialmente virtual, o passado não pode ser apreendido por nós como passado?".

\section{Memórias sobre a revista Intervalo}

A maior motivação que direcionou este estudo sobre a revista Intervalo foi o fato de - após várias pesquisas - não termos encontrado informaçōes mais completas sobre essa publicaçáo. Uma vez que foi percebida a oportunidade de pesquisa e estudos, investimos nossos esforços para encontrar ex-funcionários que pudessem - através de seus depoimentos, lembranças, fotografias e outros materiais - ajudar a reconstruir a história do semanário.

Inicialmente, nâo tínhamos ideia da importância ou relevância que esta pesquisa historiográfica teria para o meio acadêmico ou para o meio da comunicação pelo fato de não termos encontrado em arquivos e nem com a própria editora informaçóes sobre a revista. Na pesquisa inicial fizemos uma descoberta que nos incentivou a ir adiante: a revista Intervalo havia sido a primeira revista da época a tratar exclusivamente de assuntos relacionados à televisão e a divulgar a programaçáo televisiva de todos os canais do Brasil. A partir dessa informação e sabendo, através da confecção da pesquisa de mestrado ${ }^{3}$ no Programa de Pós-Graduação na Universidade Federal de Juiz de Fora (UFJF), da história televisiva nacional e a importância que o desenvolvimento da TV teve durante os anos 1960, entendemos que a revista teve também grande importância para a história dos meios de comunicação, especialmente por ter assumido o papel de divulgadora dos programas e conteúdos televisivos.

A Hemeroteca Digital da Biblioteca Nacional ${ }^{4}$ possui atualmente diversos acervos digitalizados de vários impressos, inclusive todas as ediçóes digitalizadas de Intervalo. A consulta ao acervo permitiu que, através do expediente das revistas, localizássemos uma

\footnotetext{
Para saber mais, ver: Magnolo (2018).
}

4 A Fundação Biblioteca Nacional oferece aos seus usuários a Hemeroteca Digital Brasileira, portal de periódicos nacionais que proporciona ampla consulta, pela internet, ao seu acervo de periódicos - jornais, revistas, anuários, boletins etc. - e de publicações seriadas. Nesse espaço, pesquisadores de qualquer parte do mundo passam a ter acesso, inteiramente livre e sem qualquer ônus, a títulos que incluem desde os primeiros jornais criados no país a jornais extintos no século XX. A consulta, possível a partir de qualquer aparelho conectado à internet, é plena e avançada. Pode ser realizada por título, período, edição, local de publicação e palavra (s). Além da chancela do Ministério da Cultura, a Hemeroteca Digital Brasileira é reconhecida pelo Ministério da Ciência e Tecnologia e tem o apoio financeiro da Financiadora de Estudos e Projetos (Finep), o que tornou possível a compra dos equipamentos necessários e contratação de pessoal. Disponível em: http://bndigital.bn.gov.br/hemeroteca-digital/. Acesso em: 27 jun. 2017. 
fonte, a jornalista Marilda Varejão - que trabalhou na revista de outubro de 1971 até o fechamento em agosto de 1972 - que nos direcionou para outras fontes. Por meio dessa primeira indicação, chegamos a cinco nomes: Eduardo Ribeiro, que trabalhou na Editora Abril como offce boy e depois como repórter de vários impressos entre 1965 e 1975; Esníder Pizzo, companheiro de Intervalo com Marilda, entrou em 1971 e ficou até o fechamento em 1972, inicialmente como editor de texto e posteriormente como redator chefe; Thomaz Souto Corrêa, que por muitos anos integrou a chefia dos grupos, foi parte da diretoria e até hoje - desde 1956 - trabalha na Abril; Ágata Messina, redatora chefe e depois editora de texto entre 1969 e 1972; e Laís de Castro, que ficou na Intervalo entre 1967 e 1968, primeiro como estagiária e depois como repórter.

Depois das entrevistas iniciais, alguns nomes foram citados pelos entrevistados e isso nos deu um novo direcionamento, que resultou em mais duas baterias de gravaçóes. Entrevistamos 12 pessoas e já temos reunidas mais de 300 páginas em transcriçôes e 23 horas de gravação de áudio e imagens. O contato com todos os entrevistados foi feito através de e-mail, o agendamento se deu de acordo com a disponibilidade de cada entrevistado. Foram realizadas entrevistas em São Paulo, Indaiatuba, Vinhedo, Rio de Janeiro e Petrópolis. Em sua maioria, aconteceram nas residências de nossos entrevistados, com exceçáo de Eduardo Ribeiro e Thomaz Souto Corrêa, que preferiram nos receber em suas empresas.

A elaboração do roteiro de entrevistas foi um momento crucial, seguimos com o modelo semiestruturado e buscamos elaborar questôes que abrangessem, em especial, toda a experiência do entrevistado na revista Intervalo, bem como suas principais características. Ao todo foram 21 questōes que foram respondidas em um tempo médio de uma hora e quarenta minutos. Decidimos fazer entrevistas semidiretivas temáticas, pois achamos que seria a melhor forma de conseguir as informaçôes de que precisávamos.

Através da coleta desses depoimentos conseguimos, dentre outras coisas, recuperar a história da revista Intervalo. Um ponto enriquecedor para a pesquisa foi conseguir entrevistar pessoas de diferentes épocas e fases da revista, bem como de diferentes áreas da redação, ampliando ainda mais a visão e a dimensão historiográfica da nossa pesquisa, confirmando ou negando algumas de nossas hipóteses.

\begin{tabular}{|c|c|c|c|}
\hline Entrevistado & $\begin{array}{c}\text { Data da } \\
\text { entrevista }\end{array}$ & $\begin{array}{c}\text { Quando trabalhou } \\
\text { na Intervalo/ } \\
\text { Editora Abril }\end{array}$ & Funçáo \\
\hline Esníder Pizzo & $21 / 02 / 2017$ & out./1971 a ago./1972 & $\begin{array}{c}\text { Editor de texto/ } \\
\text { Redator Chefe }\end{array}$ \\
\hline Eduardo Ribeiro & $22 / 02 / 2017$ & abr./1969 a 1975 & Office boy/Repórter \\
\hline
\end{tabular}




\begin{tabular}{|c|c|c|c|}
\hline $\begin{array}{c}\text { Thomaz Souto } \\
\text { Corrêa }\end{array}$ & $23 / 02 / 2017$ & 1956 a 2017 & $\begin{array}{c}\text { Repórter/Diretor de } \\
\text { grupos/Conselheiro }\end{array}$ \\
\hline $\begin{array}{c}\text { Milton Coelho } \\
\text { da Graça }\end{array}$ & $14 / 03 / 2017$ & fev./1966 a out./1967 & Redator principal \\
\hline Ágata Messina & $16 / 03 / 2017$ & out./1969 a ago./1972 & $\begin{array}{c}\text { Redatora/Editora } \\
\text { de texto }\end{array}$ \\
\hline Marilda Varejão & $19 / 03 / 2017$ & out./1971 a ago./1972 & Repórter/Redatora \\
\hline Jaime Figuerola & $10 / 05 / 2017$ & set./1963 a dez./1966 & Departamento de arte \\
\hline $\begin{array}{c}\text { Adalberto } \\
\text { Cornavaca }\end{array}$ & $11 / 05 / 2017$ & jan./1963 a set./1967 & Chefe de arte \\
\hline Rubens Jardim & $12 / 05 / 2017$ & abr./1970 a ago./1972 & Departamento de arte \\
\hline Dulcília Buitoni & $12 / 05 / 2017$ & nov./1970 a ago./1972 & Repórter \\
\hline Laís de Castro & $13 / 05 / 2017$ & mar./1967 a nov./1968 & Estagiária/Repórter \\
\hline Flávio Tiné & $13 / 05 / 2017$ & ago./1970 a ago./1972 & Repórter/Redator \\
\hline
\end{tabular}

Tabela 1- Quadro dos entrevistados. Organização cronológica de acordo com a data das entrevistas. ${ }^{5}$

Como pudemos observar, a revista Intervalo (1963-1972) foi um dos mais importantes veículos que surgiram entre as décadas de 1960 e 1970 valorizando temas relativos à televisão. Apesar de ser muito atento ao mercado dos meios de comunicaçáo, a inspiração de Victor Civita (jornalista e fundador da editora) para o lançamento da Intervalo veio dos Estados Unidos, de uma das revistas mais famosas da época: a TV Guide, uma publicação de formato pequeno, ${ }^{6}$ que continha todas as programaçóes televisivas, cobrindo o continente norte-americano de costa a costa. Essa forma de comunicar a programaçáo e deixar o telespectador informado para que ele pudesse acompanhar os programas, filmes e seriados prediletos chamou a atenção de Victor Civita, que quis replicar essa ideia no Brasil, como apontado por Corrêa:

Então a ideia era assim: televisão estava ficando forte, estava começando a acontecer novela e tal, vamos fazer uma revista. Ela cobria televisão, não era para cobrir fofoca, e aí, no meio desse começo, se você ver a capa você vai ver isso, tinha muito os artistas, entrevista com os artistas, não tinha fofoca tipo "fulano está com fulano", não tinha nada disso. Era uma tentativa, digamos assim, de fazer um jornalismo em cima de televisão. E aí, começa-se a descobrir uma coisa interessante que é assim:

5 Para este artigo, não será possível utilizar trechos dos depoimentos de todos os entrevistados. Buscamos, na medida do possível, trazer citações de pessoas que participaram de diferentes fases da revista, com o objetivo de abranger nossa exposição sobre a revista Intervalo.

6 A revista tinha $19 \mathrm{~cm}$ de altura por $14,5 \mathrm{~cm}$ de largura. 
quando uma novela está fazendo sucesso, quem vai para capa não é o artista, é o personagem né, você quer a identificação da leitora direta com o personagem que ela vai ver de noite [...]. (Thomaz Souto Corrêa, 2017).

A publicação era semanal e chegava às bancas toda quinta-feira. Inicialmente, sua proposta era cobrir a programação televisiva de todo Brasil - Rio de Janeiro, São Paulo, Belo Horizonte, Curitiba e Salvador - e trazer pequenas reportagens também relacionadas com os programas, shows, telenovelas, entre outros. Além de trazer algumas seçóes temáticas ${ }^{7}$ - todas sempre valorizando assuntos e astros da TV -, o foco era divulgar seu maior diferencial: a programação televisiva. ${ }^{8} \mathrm{O}$ alvoroço da nova tecnologia fez com que a década de 1950 presenciasse a intensificação da industrialização e o aumento considerável da migração das áreas rurais para as urbanas (Mattos, 2010). No início do desenvolvimento dos meios de comunicação de massa, o rádio era a principal fonte de informaçôes da população nas grandes cidades e, depois, veio a emergência da TV, que se transformou no mais importante meio de comunicaçáo de massa do Brasil, cujo processo de urbanização ocorreu simultaneamente com o desenvolvimento econômico e social. Em 1950, por exemplo, o Brasil contava com uma populaçáo de 51.944.3979 sendo que, segundo Mattos (2010), 20\% era urbana e $80 \%$ vivia na área rural. Apesar dessa discrepância numérica, o mercado brasileiro estava otimista e a produção de aparelhos de televisão se mostrava significativa já em 1957, quando foram produzidos $81.326^{10}$ aparelhos de TV - número que, apesar de expressivo, não chegava

7 Entre as seções de maior prestígio estavam "Intervalo para Conversa", que era uma página com trechos de cartas enviadas pelos leitores. As cartas geralmente traziam elogios à revista e também perguntas sobre algum ator/atriz, cantor/cantora; "O que eles disseram", que funcionava de acordo com a lógica da carta do leitor, só que eram falas dos artistas com relação a um determinado programa, acontecimento, astro da TV; "Jornal da TV", que informava sobre todos os programas, de todas as emissoras do Brasil, também em forma de pequenas notas e com alguns destaques de acordo com o que foi mais visto ou comentado ao longo da semana; e "Bola Branca, Bola Preta", onde a revista fazia pequenos comentários, tanto positivos (Bola Branca) como negativos (Bola Preta), com relação ao que acontecia na televisão.

8 De acordo com Bergamo (2010), os anos 1960 representaram para a TV brasileira um momento-chave, já que foi nesse período que várias práticas televisivas foram criadas e consolidadas, assim como outras foram abandonadas ou profundamente transformadas. É nesse momento, inclusive, que o aparelho de televisão deixa de ser "artigo de luxo" para se popularizar, mostrando que a TV passou a ter um público diferente daquele do rádio, teatro ou do cinema. A "grade" de programação das emissoras é aquilo que, de certa maneira, materializa a noção que esses profissionais têm de seu público. Foi a partir de 1960 que a televisão começa a definir uma "forma" - expressa, entre outras coisas, por meio dessa "grade" - para si mesma em função disso. A noção de público elaborada nos anos 1960 serviu de base - e, com isso, de "molde" - para a redefinição posterior da TV.

9 IBGE - Conselho Nacional de Estatística. Anuário Estatístico do Brasil - 1960, ano XXI, p. 24. Disponível em: https://biblioteca.ibge.gov.br/visualizacao/periodicos/20/aeb_1960.pdf. Acesso em: 24 maio 2020.

10 IBGE - Conselho Nacional de Estatística. Anuário Estatístico do Brasil - 1960, ano XXI, p. 87. Disponível em: https://biblioteca.ibge.gov.br/visualizacao/periodicos/20/aeb_1960.pdf. Acesso em: 24 maio 2021. 
nem perto das $356.400^{11}$ unidades de aparelhos de rádio.

Logo em 1951, por exemplo, os primeiros receptores que foram produzidos chegaram à contagem de 11.000. Depois disso, nos próximos anos - de 1955 a 1961 - foram inauguradas 21 novas emissoras, que marcaram a expansão da televisão como rede de imagens nas principais cidades do país (Barbosa, 2010). Em 1960, já existiam mais de 15 emissoras de televisão operando nas mais importantes cidades do país. Simóes (1986, p. 45) usa, para esse momento, a expressão "A TV se estende"12 já que, depois de algumas experiências bem sucedidas, a televisão amplia seu campo de ação reafirmando assim seu prestígio e "se credencia ainda mais como veículo de publicidade, começando a derrubar o grande obstáculo comercial à sua expansáo: a relativa pequenez do seu raio de cobertura". O desenvolvimento e expansão iniciais aconteceram de uma maneira rápida e eficaz, com emissoras de caráter nacional, mas também com muitos canais regionais (Barbosa, 2010).

É possível observar por meio dos depoimentos que tanto a televisão quanto as publicidades que circularam naquela época - em especial na revista Intervalo -, mostravam a ideia de que a TV era parte da rotina de uma família. Mais do que isso, de acordo com Thomaz Souto Corrêa (2017), os programas se comunicavam com as jovens adolescentes e com as donas de casa que queriam acompanhar a vida de seus músicos e artistas preferidos.

Com a proposta de disseminar o conteúdo televisivo, a publicação da Editora Abril direcionava seus esforços para os temas mais comentados e os programas mais assistidos pelo telespectador. Adalberto Cornavaca (2017) afirma que "o que prevalecia era aquilo que o público mais curtia, então, se o público curtia novelas, sempre os artistas de novelas ocupavam o primeiro plano. Na época dos festivais de MPB, os artistas do festival ocupavam o primeiro plano". Ficou claro na fala dos depoentes que, em função disso, a programação passou a ser pensada a partir da adaptação à rotina dos lares brasileiros, especialmente, a partir de uma divisão de horários que buscava um melhor enquadramento entre o trabalho e diversão.

Junto com a ebuliçấo da programação televisiva, a Intervalo foi se construindo e se adaptando à nova realidade dos meios de comunicaçáo de massa. É fato que, como qualquer outro veículo de comunicação, a revista noticiava o que acontecia, trazia artistas que estavam fazendo sucesso com as primeiras telenovelas, cantores que surgiram naquele período graças aos mais variados programas musicais, bem como

11 IBGE - Conselho Nacional de Estatística. Anuário Estatístico do Brasil - 1960, ano XXI, p. 87. Disponível em: https://biblioteca.ibge.gov.br/visualizacao/periodicos/20/aeb_1960.pdf. Acesso em: 24 maio 2021.

12 Apesar de não utilizar o mesmo termo de Inimá Simões, a historiadora Marialva Barbosa apresenta uma reflexão sobre o fato de a televisão ir muito além do aparelho televisor. Como pudemos ver através das publicidades, segundo a autora, mesmo antes de seu explosão inicial a TV já fazia parte do cotidiano das pessoas como "imaginação". "Antes de ser imagem, como expectativa, a televisão já estava colocada definitivamente na sala de visitas do público"(Barbosa, 2010, p. 21). 
os festivais de MPB que, durante os anos 1960, ganharam força e um público cativo, tanto a plateia que acompanhava nos auditórios, como os telespectadores que se reuniam em casa para assistir pela TV. De acordo com Thomaz Souto Corrêa (2017), as revistas cobriam os acontecimentos, os programas, ou seja, tudo que estava dando certo, na tentativa de influenciar e orientar o olhar do leitor para a realidade do mercado televisivo daquele momento, não somente programas brasileiros como, por exemplo, os Festivais de MPB, O Fino da Bossa, Os Trapalhóes, telenovelas, entre outros, mas também seriados americanos, como foi o caso de Os Intocáveis, Perry Mason, Lessie, Durango Kid, entre outros. Além disso, a revista tinha como principal objetivo, deixar o leitor em dia com tudo de interessante que acontecia no mundo da "caixinha de vídeo". O semanário possuía uma seção chamada "Náo perca este programa" onde em toda edição indicava a "transmissáo mais promissora" - aquela que o telespectador não podia perder -, que vinha acompanhada de uma ficha com dados interessantes e curiosidades.

Assim, pode-se afirmar que a chegada da televisão no Brasil provocou diversas mudanças, aperfeiçoamentos técnicos e originou uma nova forma de comunicar o que acontecia nos meios de comunicaçáo. O impacto para a Intervalo $^{13}$ foi muito grande, porque ao mesmo tempo que a TV era uma novidade no Brasil, escrever sobre televisáo, realizar coberturas de programas também era uma significativa novidade. Adalberto Cornavaca foi um dos primeiros profissionais de arte que passou pela Intervalo e participou da primeira ediçáo do semanário, quando foi lançado. Ele comenta sobre as mudanças que foram necessárias para a produção de uma revista que falava exclusivamente sobre televisão.

E nós tínhamos como forte também a programação de todas as coisas que aconteciam na TV. Só que como estava tudo no começo, era uma trapalhada, porque o canal falava: 'Olha, hoje às 16:30 vai ter tal coisa', só que depois às 16:30 tinha outra coisa, aí era difícil de consertar de última hora, quando dava a gente consertava, quando não, saía errado, aí o editor reclamava, mas depois de um tempo melhorou. Quando melhorou, os jornais viram quanto era importante ter a programação da TV impressa, que todos os jornais começaram a dar a programação e aí a Intervalo foi perdendo um pouco de leitores por causa disso, só que foi ganhando depois novamente no auge das novelas. (Adalberto Cornavaca, 2017).

O impacto da TV foi grande e definitivo na organização dos outros meios de comunicação, não somente na forma de produção, mas no relacionamento que começou a ser construído entre os canais de TV e as redaçóes; entre os jornalistas e os cantores; entre os redatores e as gravadoras. Dessa mudança, nasceu uma nova forma de pensar o

13 As informações que pudemos angariar até o momento sobre o impacto da revista no país estão presentes nos depoimentos, mas também no nosso entendimento sobre o contexto da emergência da TV no Brasil, bem como da cultura de massa, que culminaram na criação das revistas especializadas em TV. Sabe-se que os exemplares foram distribuídos através das bancas de rua e num segundo momento, de assinaturas, porém não temos os números precisos. 
jornalismo de televisão, mas também a perceber os concorrentes que passaram a entender a importância de trazer para suas páginas informaçôes sobre os programas, a programação diária, fotos e reportagens.

Antes das novelas da TV, existiam as fotonovelas. Eram revistas que traziam uma espécie de história em quadrinhos com fotos e a primeira a fazer isso da Abril foi a Capricho. A Capricho era uma revista de fotonovelas, depois com o tempo, se transformou na revista que é hoje, das meninas, com todos os assuntos que elas gostam. Então, Intervalo praticamente matou as revistas de fotonovelas e cresceu com as novelas de TV, depois com o tempo, como todos esses assuntos eram tratados por todo mundo, de todos os jornais, a Intervalo começou a chegar no seu fim. (Adalberto Cornavaca, 2017).

Apesar de tudo, de acordo com Esníder Pizzo (2017), a regra que valia era publicar o que o público mais gostava de ver nas telas da TV. A fotografia foi importante porque dessa forma as fấs conseguiam guardar a imagem de seu ídolo - coisa que antes não acontecia no rádio, por exemplo, onde as fầs só tinham contato com seus ídolos através de sua voz. Thomaz Souto Corrêa (2017) afirma ser importante ressaltar que ao longo das décadas de 1960 e 1970 a televisão se modificou: os programas musicais, que eram os favoritos no início dos anos 1960, deram lugar às telenovelas e aos programas humorísticos, e a partir da década de 1970 os noticiários ganharam mais espaço. A semana anterior à nova edição da revista sempre esteve refletida em suas páginas, que passou, durante sua existência, por três fases, sempre buscando se adaptar às mudanças de postura de seu mercado consumidor e do que era transmitido pela televisão.
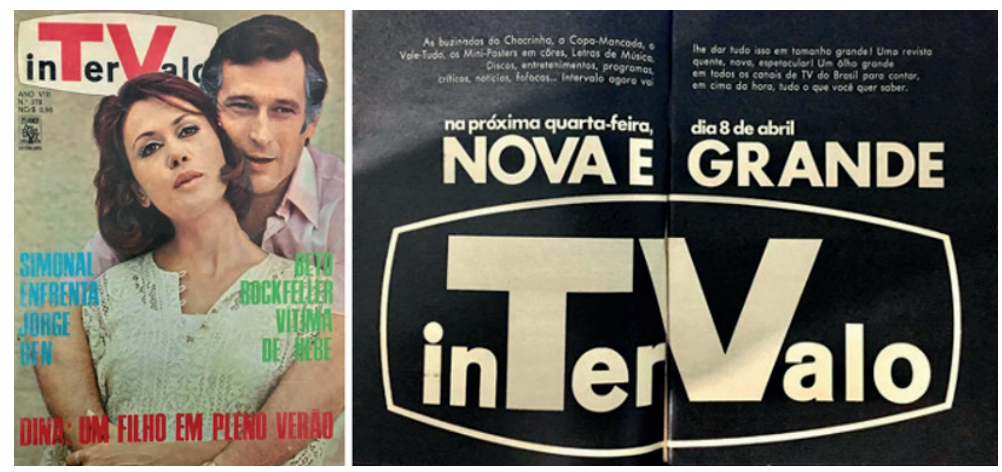

Figura 2 - Revista Intervalon. 378: capa da última versão pequena do semanário antes de mudar de tamanho, acompanhada do anúncio sobre a mudança nas páginas 10 e $11 .^{14}$

Fonte: acervo pessoal de Talita Souza Magnolo.

14 O texto do anúncio dizia: "As buzinas do Chacrinha, a Copa-Mancada, o Vale-Tudo, os Mini-Posters em côres, Letras de Música, Discos, entretenimentos, programas, críticas, notícias, fofocas... Intervalo agora vai lhe dar tudo isso em tamanho grande! Uma revista quente, nova, espetacular! Um ôlho grande em todos os canais de TV do Brasil para contar, em cima da hora, tudo o que você quer saber". 
$\mathrm{Na}$ primeira fase, trazia seçōes sobre assuntos de televisão, ou seja, realizava uma cobertura jornalística mais extensa em cima de eventos, programas, competiçóes musicais, bastidores, todavia, o forte e a novidade eram a programação.

$\mathrm{Na}$ verdade, o objetivo maior da Intervalo era um negócio chamado programaçáo porque naquela época a programação não mudava, então você publicava toda semana a programação dos canais de televisão e isso não saía no jornal. Então o público eu acho que era desde tiete, que na época essa palavra não existia, chamava fă até as senhoras que viam televisáo em casa e que queriam saber os horários dos programas, elas compravam por causa da programaçấo. Tinha um cara que só fazia programação, ia nos canais, pegava a programação, fazia só isso. $\mathrm{O}$ resto, tinha uma, duas ou três seçõezinhas e o resto eram reportagens que em princípio acompanharam a programação e depois as reportagens cresceram mais e como a programação começou a esculhambar, porque você falava que ia ser às $19 \mathrm{~h}$, era às $21 \mathrm{~h}[\ldots]$ então, não deu certo, aí ela virou uma revista de reportagem e fofoca. (Laís de Castro, 2017).

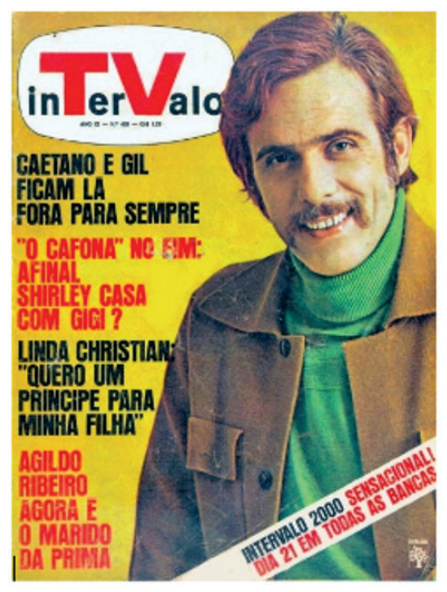

Figura 3 - Revista Intervalon. 458: capa com o anúncio da troca do nome da revista para Intervalo 2000. Fonte: Astros em Revista. ${ }^{15}$

Na sua segunda fase, a revista cresceu de tamanho ${ }^{16}$ - antes ela era no formato de uma revista de quadrinhos infantil e depois passou a ter o tamanho normal de revista - e esbarrava em assuntos mais voltados para a vida das celebridades e fofocas. Thomaz Souto Corrêa (2017) afirma que antes você via nas capas os artistas, com o passar do tempo, os artistas começaram a se confundir com os personagens que faziam na TV, ou seja, sua

15 Disponível em: http://astrosemrevista.blogspot.com.br/2015/08/capas-intervalo-379-458.html. Acesso em: 2 mar. 2021.

16 A revista passa a medir $3 \mathrm{~cm}$ de altura por $24,5 \mathrm{~cm}$ de largura, respeitando o tamanho tradicional das revistas brasileiras. 
vida privada ganhou espaço e isso fez com que a Intervalo perdesse sua proposta inicial, como pode-se perceber no depoimento a seguir:

Quando ela vai do formato pequeno para o formato grande, ela vai enfrentar uma briga na rua que já era a fofoca, aí ela perde a característica de ser assim, a cobertura da televisão para começar a botar fofoca também. Quem vende mais, quem vende menos, quais são os dramas e as angústias que os artistas, os grandes artistas estáo passando. E teve um momento, já mais recente em que as revistas se dividem, tem as revistas que cobrem só novela e aí vivem para os personagens das novelas [...] uma das revistas da Abril, eu náo me lembro qual, vai fazer isso e as outras vão pelo caminho da fofoca. A Abril tinha quatro revistas de fotonovela: Noturno, Capricho, Ilusão, Contigo, quatro! A Capricho vendia uma enormidade de revistas, coisa de 500 mil exemplares, quando era fotonovela. Quando entra a telenovela, a fotonovela começa a perder a graça, então todas as novelas da Abril $O$ Grande Hotel, como é que chama, O Sétimo Céu, todas começam a vender menos e aí, entram na cobertura da televisão por intermédio das novelas e das fofocas. Aí muda o panorama, Intervalo muda com esse panorama. (Thomaz Souto Corrêa, 2017).

A terceira fase é representada pela mudança do nome da revista para Intervalo 2000, no dia 21 de outubro de 1971, permanecendo assim até seu final precoce em agosto de 1972. De acordo com Thomaz Souto Corrêa (2017), a revista nesse momento já estava cansando por exaustáo, a mudança do nome foi uma tentativa que, segundo ele, já sabia que náo ia dar certo, porque teve como principal proposta entrar em um tipo de jornalismo de fofoca e sensacionalismo.

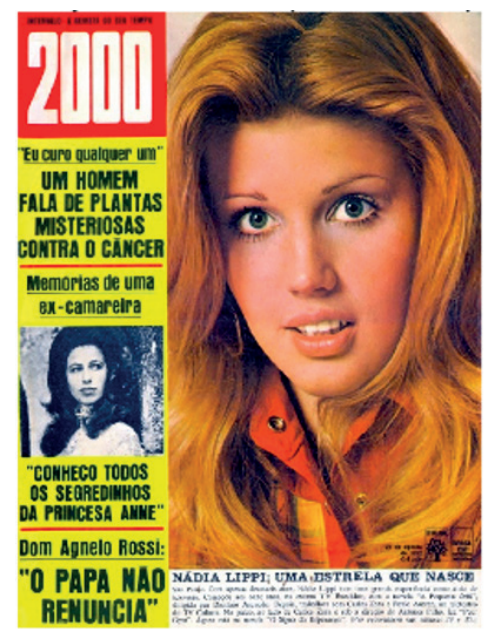

Figura 4 - Revista Intervalon. 501: última edição da revista (21/08/1972).

Fonte: acervo pessoal de Talita Souza Magnolo. 
De acordo com Ágata Messina (2017), a mudança de nome foi sugestão do diretor da revista da época, o italiano Alessandro Porro - chamado carinhosamente pelos funcionários de Sandro -, que teve como inspiraçáo uma revista italiana de grande venda parecida com a revista Caras da Editora Abril chamada Nouvelle 2000.

[...] a Europa está cheia de nobre falido, uma aristocracia falida, tem uma gama de atores, atrizes que também se intercalam, França, Itália, Alemanha, tem aquelas estaçóes de esquis, que se reúnem [...] Entáo, a Nouvelle 2000 tinha um perfil, digamos, tipo Caras hoje. Nós não tínhamos isso, nem público para isso, só que o Sandro disse: 'Não, vai dar certo!'. Eu disse: 'Sandro, você é muito meu amigo, mas não vai dar certo, o Brasil não tem aristocracia ferrada sabe, e claro que um cara de classe média baixa gosta de saber do príncipe de não sei onde, a aristocracia sempre exerceu muita fantasia né'. [...] Não deu, não deu. Aí ela passou a chamar Intervalo 2000, aí acabou. Porque aí deixou de ser só televisão, deixou de ser, o mercado é uma coisa difícil, no que a Intervalo 2000 foi minguando, a Bloch lançou a Amiga, claro, grande também, mas com aquela perspectiva da Intervalo entendeu, e aí acabou que a revista começou a dar para trás, foi uma pena, porque era uma revista que vendia muito $[. .$.$] , eu acho que ela poderia ter durado um pouco mais, talvez.$ (Ágata Messina, 2017).

Eventualmente, com o passar do tempo, a Intervalo perdeu seu espaço para outras revistas com o mesmo perfil de outras editoras, mas também para publicaçōes da própria Editora Abril que ganharam mais investimentos e interesse dos leitores. No tempo que esteve em circulação, a revista chegou a vender, de acordo com Adalberto Cornavaca (2017), 250 mil exemplares por semana, considerado um grande sucesso para a época - outros entrevistados como Milton Coelho da Graça (2017) e Thomaz Souto Corrêa (2017) mencionaram também essa tiragem, variando entre 200 e 250 mil exemplares por semana. Dentro das mais variadas adversidades tecnológicas, temáticas e mudanças de comportamento de seu público leitor, a revista Intervalo fez história ao ser a primeira revista que trouxe em suas páginas a programaçáo televisiva de todo Brasil.

A produçáo naquele período é vista por Adalberto Cornavaca (2017) como artesanal, artística, pois envolvia paixão pelo trabalho e muita criatividade. Os profissionais de arte da Intervalo, por exemplo, tinham que ser artistas plásticos ou desenhistas profissionais para serem capazes de montar a primeira versão da revista $\mathrm{e}$ organizá-la como uma verdadeira obra de arte. Para corrigir algum erro de impressão, era preciso fazer uma colagem por cima, cuidadosamente. A arte que estava em tanta efervescência nas telas da televisão, era trazida para as redaçóes: "Era apaixonante a época, saía às $23 \mathrm{~h}$, minha esposa que náo gostava, saíamos altas horas, para fechar a revista com paixão, ninguém reclamava, era uma época romântica" (Adalberto Cornavaca, 2017).

As entrevistas nos mostraram também o envolvimento emocional por parte dos entrevistados que em todo momento afirmaram que a uniáo, ousadia e alegria da redação 
fez toda diferença para a revista Intervalo, que se posicionou como o primeiro impresso semanal da época a trazer a programação da televisão de todo país e de todos os canais. Esse grande impacto foi sentido pelo público que pertencia, inicialmente, às revistas de fotonovelas e que, aos poucos, migrou para a televisão e seus inúmeros programas.

\section{Considerações Finais}

Ao longo dos estudos acerca da memória, bem como a utilização da metodologia de História Oral, percebemos que a história é única e, portanto, tem seu valor e merece ser preservada e experimentada. $\mathrm{O}$ uso das narrativas históricas faz parte do nosso cotidiano e merecem ser guardadas para geraçóes futuras e aqueles depoimentos que possuem sentido social devem ser apropriados pela sociedade pois articuladas, as narrativas tecem uma nova memória social e plural. A recuperaçáo da história da revista Intervalo, através de entrevistas de história oral, deixou evidente a revelação e o entendimento de novas óticas e interpretaçóes sobre um período histórico já muito estudado, mas que possuem vertentes e histórias náo contadas que, uma vez compartilhadas, fornecem uma nova ressignificação das ideias que se tem sobre o passado. Além disso, este foi o único método que se tornou possível o resgate e a recuperaçáo da história da revista, bem como suas características.

O semanário veio com a proposta de modernizaçáo do meio impresso e quis, desde seu primeiro exemplar, dialogar de maneira exaustiva com todos os passos e caminhos escolhidos pela televisão, se tornando assim, porta-voz da programação televisiva, novidades no mundo dos astros e celebridades e informaçóes sobre o mundo da TV. Pudemos observar que uma das estratégias adotadas foi a evoluçáo da revista, que passou por três fases distintas. Entretanto, em todos os momentos de sua existência, a Intervalo nunca deixou de fazer mençóes sobre os programas, os astros em alta e acontecimentos recentes do mundo midiático. Mesmo que cada fase tivesse um propósito diferente, fosse tratar sobre a televisão e seu bastidor ou fazer fofoca e matérias mais sensacionalistas, falando dos segredos das celebridades ou elogiando um programa, todas tinham como cerne a televisão.

Esta pesquisa ainda está em andamento e pretende analisar os depoimentos sob diferentes aspectos, desde a relaçáo da revista com o meio midiático, até sua contextualização em um período militar, suas características de produção, curiosidades e singularidades. Pudemos comprovar neste artigo que o semanário da Editora Abril teve grande importância no mercado impresso da época, mas também no meio televisivo que construiu uma relaçấo de proximidade e fidelização muito grande ao longo dos anos. Em tempo que a televisão evoluiu e se modificou, a revista acompanhou essas mudanças e melhorias, sempre divulgando massivamente os programas, a programaçáo, os cantores, astros e celebridades da TV. 


\section{Referências}

BENJAMIN, Walter. Magia e técnica, arte e politica: ensaios sobre literatura e história da cultura. Tradução Sérgio Paulo Rouanet. São Paulo: Brasiliense, 2012. (Obras Escolhidas, v. 1).

BERGAMO, Alexandre. A reconfiguração do público. In: RIBEIRO, Ana Paula Goulart; SACRAMENTO, Igor; ROXO, Marco (Org.). História da televisão no Brasil. São Paulo: Contexto, 2010. p. 59-83.

BERGSON, Henri. Matéria e memória: ensaio sobre a relação do corpo com o espírito. São Paulo: Martins Fontes, 2010.

DAVID, Priscila. História Oral: metodologia do diálogo. Patrimônio e Memória, São Paulo, v. 9, n. 1, p. 157-170, jan./jun. 2013.

HALBWACHS, Maurice. Memória coletiva. São Paulo: Vértice, 1990.

HUYSSEN, Andreas. Culturas do passado-presente: modernismos, artes visuais, políticas da memória. Coordenação Tadeu Capistrano. Tradução Vera Ribeiro. Rio de Janeiro: Contraponto: Museu de Arte do Rio, 2014.

HUYSSEN, Andreas. Seduzidos pela memória: arquitetura, monumentos, mídia. Rio de Janeiro: Aeroplano, 2000.

LE GOFF, Jacques. História e memória. Campinas: Editora da Unicamp, 2003.

MAGNOLO, Talita Souza. A construção narrativa do Festival de MPB de 1967 nas páginas da revista "Intervalo". Dissertação (Mestrado em Comunicação) - Universidade Federal de Juiz de Fora, Juiz de Fora, MG, 2018. Disponível em: https://repositorio.uff.br/jspui/handle/ufff/6634. Acesso em: 1 fev. 2020.

NORA, Pierre. Entre memória e História: a problemática dos lugares. Projeto História, São Paulo, n. 10, p. 7-28, 1993.

POLLAK, Michael. Memória e identidade social. Estudos Históricos, Rio de Janeiro, v. 5, n. 10, p. 200-212, 1992.

POMIAN, Kryysztof. Memória: atlas, coleção, documento/monumento, fóssil, memória, ruína/ restauro. In: GIL, Fernando (Coord.). Sistemática. Porto: Imprensa Nacional: Casa da Moeda, 2000. p. 507-516. (Enciclopédia Einaudi, v. 42).

PORTELLI, Alessandro. História oral como arte da escuta. São Paulo: Letra e Voz, 2016.

THOMPSON, Paul. A voz do passado: História Oral. São Paulo: Paz e Terra, 1992.

\section{Fontes orais}

CASTRO, Laís de. [maio 2017]. Entrevistadora: Talita Souza Magnolo. São Paulo, SP, 13 maio 2017. CORNAVACA, Adalberto. [maio 2017]. Entrevistadora: Talita Souza Magnolo. Vinhedo, SP, 
11 maio 2017.

CORRÊA, Thomaz Souto. [fev. 2017]. Entrevistadora: Talita Souza Magnolo. São Paulo, SP, 23 fev. 2017.

GRAÇA, Milton Coelho da. [mar. 2017]. Entrevistadora: Talita Souza Magnolo. Rio de Janeiro, RJ, 14 mar. 2017.

MESSINA, Ágata. [mar. 2017]. Entrevistadora: Talita Souza Magnolo. Rio de Janeiro, RJ, 16 mar. 2017.

PIZZO, Esníder. [fev. 2017]. Entrevistadora: Talita Souza Magnolo. Indaiatuba, SP, 21 fev. 2017.

Recebido em 22/04/2019.

Versão final reapresentada em 02/02/2021.

Aprovado em 01/03/2021.

Contribuiçóes dos autores: Magnolo: gravação de depoimentos, pesquisa sobre a revista Intervalo; Henriques: discussões teóricas sobre a memória.

Fonte de financiamento: nada a declarar.

Conflitos de interesse: nada a declarar. 